\title{
Changes in Risk and the Demand for Saving
}

\author{
LOUIS EECKHOUDT \\ HARRIS SCHLESINGER
}

CESIFO WORKING PAPER NO. 2388

CATEgory 5: Fiscal POLICY, MACROECONOMICS AND GROWTH

SEPTEMBER 2008

\footnotetext{
An electronic version of the paper may be downloaded

- from the SSRN website: Www.SSRN.com

- from the RePEc website: Www.RePEc.org

- from the CESifo website: www.CESifo-group.org/wp
} 


\title{
Changes in Risk and the Demand for Saving
}

\begin{abstract}
How does risk affect saving? Empirical work typically examines the effects of detectible differences in risk within the data. How these differences affect saving in theoretical models depends on the metric one uses for risk. For labor-income risk, second-degree increases in risk require prudence to induce increased saving demand. However, prudence is not necessary for first-degree risk increases and not sufficient for higher-degree risk increases. For increases in interest rate risk, a precautionary effect and a substitution effect need to be compared. This paper provides necessary and sufficient conditions on preferences for an $\mathrm{N}^{\text {th }}$-degree change in risk to increase saving.
\end{abstract}

JEL Code: D81, E21.

Keywords: precautionary saving, prudence, stochastic dominance, temperance.

Louis Eeckhoudt

Catholic University of Mons

CORE

34 Voie du Roman Pays

1348 Louvain-la-Neuve

Belgium

eeckhoudt@fucam.ac.be
Harris Schlesinger

University of Alabama

200 Alston Hall

Tuscaloosa, AL 35487-0224

USA

hschlesi@cba.ua.edu

August 14, 2008

The authors thank Robert Reed, Robert King (the editor) and an anonymous referee, as well as seminar participants at Georgia State University, University of Illinois, University of Konstanz, University of Pennsylvania, University of Verona, University of Wisconsin and Temple University for helpful comments on an earlier draft of this paper. 


\section{Introduction}

The effect of risk on saving is a key element in understanding the intertemporal behavior of consumption. Early permanent-income-hypothesis models that lead to certainty equivalence have largely been replaced by models attempting to explain the observed positive correlation between income disturbances and consumption. To a large degree, these models assume that market incompleteness - the lack of a market for fully insuring particular types of risks - can explain some of these empirically observed phenomena.

Much of this literature has focused on labor-income risk at the household level. In addition to measurement errors, there is also the question as to which particular measure of risk is the most appropriate. This risk metric used is not innocuous. Moreover, whereas most empirical analyses deal with changes in risk, their theoretical counterparts all consider how models with uncertainty differ from those with certain income streams. ${ }^{1}$

\footnotetext{
${ }^{1}$ Good overviews of both the theoretical and empirical literature on this topic can be found in Kimball (1992), Browning and Lusardi (1996), Huggett and Ospina (2001) and Carroll and Kimball (2008).
} 
A second and much smaller strand of literature has dealt with the effect of risky interest rates on saving. As opposed to the case where only future labor income is risky, a risky interest rate implies that "giving up a dollar's worth of certain present consumption does not result in a certain increase in future consumption." (Sandmo 1970, p. 353) Thus, a risky interest rate has different implications for its effect on saving than does risky labor income.

This paper considers very general types of changes in each of these two sources of risk: labor-income risk and interest-rate risk. In particular, $N^{t h}$-order stochasticdominance changes in each risk are considered and conditions on preferences are derived that are both necessary and sufficient for these changes to lead to an increase in saving. In the case of labor-income risk, the increase in saving is due to a precautionary effect. In the case of risky interest income, both a precautionary effect as well as a type of substitution effect need to be weighed against each other to determine the overall effect on saving.

Establishing these results for general $N^{t h}$-order changes in risk is not just a theoretical whim. Oftentimes establishing stochastic dominance of lower orders is not possible. Moreover, much of the extant empirical literature examines differences in risk with "risk" being measured using very different metrics. The next section explains how many of these metrics can be put into a stochastic-dominance frame- 
work. The results are consistent with the premise that the higher moments of risky distributions (not just the first two moments) can be quite important. If such higher moments are affected by business cycles and other macroeconomic phenomena, this can lead to predictable saving behavior that has hitherto not been studied.

The paper proceeds as follows. In the next section, both $N^{t h}$-order stochastic dominance and an increase in $N^{t h}$-degree risk, as introduced by Ekern (1980), are defined. It is shown how several economic models of risk changes can be addressed by using this set-up. The paper then applies the general results to each source of risk. Since the conditions on preferences that are derived are both necessary and sufficient to guarantee an increase in saving, the results have strong implications for empirical modeling. For instance, seemingly innocuous assumptions made about preferences might have stronger-than-intended implications.

In the case of labor-income risk, it is shown how the most commonly used utility functions will lead to an increase in precautionary savings for any $N^{\text {th }}$-order increase in risk. The same questions are then examined for a change in the random return on savings. Here the conditions on preferences that are needed for an increase in saving are more limiting, but they are satisfied for any $N^{t h}$-order increase in risk under the common assumption of constant relative risk aversion (i.e. constant elasticity of substitution) whenever the coefficient of relative risk aversion exceeds one. 


\section{Types of Risk Changes}

In this section, various types of risk changes are defined and are shown to apply within much of the extant literature on saving. A simple two-period setting is used in order to focus on the changes in risk. The individual is assumed to make a decision in the first period, when current income is known, about how much to consume and how much to save. In each model, either future labor income or the interest rate is stochastic. The results obtained in this paper can be embedded into more complex settings, such as multiple-period models or representative-agent general-equilibrium models, in well-known and straightforward manners. ${ }^{2}$ This simplified setting allows us to better isolate the risk changes and their effects.

The types of risk changes that are considered throughout the paper are based on the property of stochastic dominance. Let $F$ and $G$ denote two cumulative distribution functions of wealth, defined over a probability support contained within the open interval $(a, b)$. Define $F_{1}=F$ and $G_{1}=G$. Now define $F_{n+1}(z)=$ $\int_{a}^{z} F_{n}(t) d t$ for $n \geq 1$ and similarly define $G_{n+1}$. The distribution $F$ dominates the distribution $G$ via $N^{t h}$-order stochastic dominance $(N S D)$ if $F_{N}(z) \leq G_{N}(z)$ for all $z$, and if $F_{n}(b) \leq G_{n}(b)$ for $n=1, \ldots N-1$. If the random wealth variables $\widetilde{y}$

\footnotetext{
${ }^{2}$ A review of how such embeddings have been handled, as well as problems that might arise, can be found in Huggett and Ospina (2001).
} 
and $\widetilde{x}$ have the distribution functions $F$ and $G$ respectively, we also will say that $\widetilde{y}$ dominates $\widetilde{x}$ via $N S D .^{3}$

Following Ekern (1980), $\widetilde{x}$ is defined as an increase in $N^{\text {th }}$-degree risk over $\widetilde{y}$ if $\widetilde{y}$ dominates $\widetilde{x}$ via $N^{t h}$-order stochastic dominance and the first $N-1$ moments for the distributions of $\widetilde{y}_{1}$ and $\widetilde{x}_{1}$ coincide. As an example, $\widetilde{x}$ is an increase in seconddegree risk over $\widetilde{y}$ if $\widetilde{y}$ dominates $\widetilde{x}$ via second-order stochastic dominance and both distributions have equal means. This is what Rothschild and Stiglitz (1970) define as a "mean-preserving increase in risk." Similarly, Menezes et al. (1980) describe a third-degree increase in risk, which they call an "increase in downside risk."

\subsection{Labor Income Risk}

First consider risk in the distribution of future labor income. While several early models have used quadratic utility to show that certainty equivalence still holds in the face of labor-income risk, others were quick to show how some canonical higherorder properties of utility would lead to very different conclusions. In particular, papers by Leland (1968) and Sandmo (1970) showed that when the utility function is separable, a positive third derivative generates a precautionary demand for saving. These papers both consider the change from a known non-stochastic level of future

\footnotetext{
${ }^{3}$ See, for example, Ingersoll (1987).
} 
labor income to a stochastic future income of equal mean.

These authors seemed content to note that the common assumption of decreasing absolute risk aversion (DARA) was sufficient to generate this precautionary saving, although no intuition was provided as to why DARA might be of importance. Kimball (1990), who labels the property of a positive third derivative of utility as "prudence," was the first to more rigorously analyze how properties of preferences are linked to precautionary saving. Much of this analysis has been incorporated into the empirical literature on consumption and saving. However, the empirical literature has utilized various measures of risk, and for many of these risk measures prudence is neither necessary nor sufficient to generate a precautionary demand for saving.

\section{Second-order risk increases}

Most of the empirical literature considers various proxies of labor income, and then compares data with differing variances. ${ }^{4}$ The underlying hypothesis is that a "riskier" labor-income stream will lead to higher precautionary saving. These empirical papers each assume a particular functional form for the distribution of labor income. Abstracting away from these distributional forms, one can infer that these changes are focused on second-order increases in risk. The variance in these

\footnotetext{
${ }^{4}$ See Carroll and Kimball (2008) for a review of some of this literature.
} 
models serves as a proxy for "risk." 5

As is shown in this paper, such risk changes are a natural extension of the theoretical models mentioned above, which all consider certainty vs. uncertainty in future earnings. In particular, their theoretical underpinnings require prudence to explain how increased risk generates more saving. In addition, this literature has been extended to examine precautionary saving over the course of the business cycle. For example, Storesletten et al. (2004) show that idiosyncratic labor income risk is countercyclical, with a higher variance (leading to more saving) during downturns in the business cycle.

\section{First-order risk increases}

Of course, variance of labor income is not the only measure used within the empirical literature. Several authors point out difficulties with the data sets employed and with the proxies used in obtaining variance measures; and they use instead proxies for the probability of job loss. ${ }^{6}$ However, an increase in the probability of becoming unemployed is not an increase in second-order risk. It is instead a first-order change in risk. An increase in the unemployment rate, by itself, would indicate a deterioration

\footnotetext{
${ }^{5}$ Generally, variance is not sufficient to guarantee a second-order increase in risk, as shown by Rothschild and Stiglitz (1970). However, when restricting the universe to a particular functional form for the probability distributions, then variance may well be sufficient.

${ }^{6}$ For example, Carroll et al. (2003), Engen and Gruber (2001) and Lusardi (1988) all show that an increase in the probability of unemployment leads to an increase in precautionary saving.
} 
in the distribution future labor income via first-order stochastic dominance. ${ }^{7}$

Again, such models generate predictions over the business cycle. For example, Parker and Preston (2005) show that precautionary saving is higher when the unemployment rate is expected to increase, but explain their result as being consistent with the notion that increased idiosyncratic risk is higher during a recession. If one considers the increased "risk" in future labor income to be a higher probability of unemployment, then one cannot use theoretical conclusions based upon prudence. Indeed, as will be shown, even a model with quadratic utility generates a precautionary demand for saving under first-degree risk increases.

In a similar vein, changes in unemployment benefits typically generate first-order changes in labor income risk. A decrease in benefit levels and/or tougher eligibility requirements leads to the same type of risk change as an increase in the probability of unemployment. ${ }^{8}$

\section{Higher-order risk changes}

Higher order risk changes also require different theoretical assumptions to generate precautionary saving. We are not aware of much empirical literature considering higher orders of risk changes. Guiso et al. (2002) do include an estimate of the third

\footnotetext{
${ }^{7}$ Interestingly, such a change need not increase the variance of future labor income. For example, as the probability of becoming unemployed approaches one, the variance would approach zero.

${ }^{8}$ See, for instance, Engen and Gruber (2001). As with much of the literature, the authors explain their precautionary demand via prudence, even though the type of risk change that they model is a first-order change.
} 
moment of risky labor income, which adds a skewness dimension to the analysis, but they limit their analysis to a triangular distribution. This adds a third-order risk to the analysis. If the distribution of labor income is asymmetric, then how the skewness of the distribution changes over the course of a business cycle would seem to be an area ripe for empirical investigation.

In addition, changes in the tax structure might beget precautionary saving. For example, Davies and Hoy (2002) show how a change from a progressive income tax to a so-called "flat tax" might actually decrease the level of third-order risk within the distribution of post-tax labor income. ${ }^{9}$

Of course, fourth and higher orders of risk changes are also possible. For example, an empirical model might find that kurtosis varies in comparing distributions of labor income, even if the first three moments are mostly identical. Would such a finding have an implication for precautionary saving?

\subsection{Interest Rate Risk}

The second source of risk that is considered is the interest rate on saving. To the best of our knowledge, such models were first formalized by Phelps (1962) and Levhari and Srinivasan (1969). Characterizations of how saving in the presence of interest-

\footnotetext{
${ }^{9}$ In actuality, Davies and Hoy (2002) consider a redistribution of wealth within the population. However, their results can easily be interpreted in terms of earnings probabilities.
} 
rate risk compares with the no-risk case were first developed by Hahn (1970) and by Sandmo (1970). ${ }^{10}$ Such cases require one to balance a substitution effect (reducing saving if the return on savings becomes riskier and, hence, less attractive) against a precautionary effect. If the precautionary motive is strong enough, in a way that is made precise in this paper, then saving will increase.

An extension to mean-preserving increases in risk was developed by Rothschild and Stiglitz (1971). But what of other types of stochastic changes in the interest rate? What will be the effect on saving? To our knowledge, no one has examined the effects of other orders of risk changes.

Most obviously, first-order risk changes would seem fairly common in real-world markets. For example news events might indicate that short-term interest rates are expected to be stochastically lower: the conditional distribution of interest rates would deteriorate in the sense of first-order stochastic dominance. But what effect, if any, would this new distribution have on precautionary saving?

Higher order risk changes also would appear to be relevant. Empirical models of short-term nominal interest rates have observed that the third and fourth moments of the distribution are important. For example, Engle (1982) explains observed

\footnotetext{
${ }^{10}$ It was interesting to us that the paper by Hahn (1970) has received relatively little attention in the literature. This may be partly due to the informal structure in Hahn's paper. He uses variance as his risk measure, but uses a heuristic graphical argument with a Bernoulli distribution for interest rates.
} 
leptokurtosis in the distribution of short-term nominal rates via heteroskedasticity. Gray (1996) obtains a similar result using a generalized regime switching model. Dutta and Babbel (2005) compare alternative functional forms of the distribution function and find that both skewness and kurtosis are significantly higher than with the standard lognormal distribution. ${ }^{11}$

Since changes in skewness and kurtosis are respectively third- and fourth-order changes in risk, one needs to ask how these measures change with respect to macroeconomic policy and/or over the business cycle. And, how do these changes affect the demand for precautionary saving?

\section{Labor Income Risk and Precautionary Saving}

Consider a consumer with a two-period planning horizon. As a base case, consider a consumer with a certain income stream of $y_{0}$ at date $t=0$ and $y_{1}$ at date $t=1$. The consumer must decide how much to save at date $t=0$. Any income that is not saved is consumed at that date. There is a fixed rate of interest $r$ for both saving and for borrowing. Savings are allowed to be negative (i.e. we allow for borrowing), so long as the amount borrowed can be repaid from the future income $y_{1}$.

\footnotetext{
${ }^{11}$ The lognormal is "standard" if interest rates are modeled via diffusion processes that are based on geometric Brownian motion.
} 
The consumer is assumed to have preferences that are intertemporally separable with a preference for smoothing consumption over time. To this end, the consumer chooses a level of saving so as to maximize her lifetime utility of consumption:

$$
\max _{s} U(s) \equiv u\left(y_{0}-s\right)+\frac{1}{1+\delta} u\left(y_{1}+s(1+r)\right),
$$

where the utility function $u$ is assumed to be strictly increasing and strictly concave and where $\delta$ represents the consumer's personal rate of discount for delaying the utility of future consumption. It is also assumed throughout this paper that $u$ is continuously differentiable

The first-order condition for (1) is

$$
U^{\prime}(s)=-u^{\prime}\left(y_{0}-s\right)+\frac{1+r}{1+\delta} u^{\prime}\left(y_{1}+s(1+r)\right)=0,
$$

which is assumed to hold at some interior value $s^{*},-y_{1}<s^{*}(1+r)<y_{0}(1+r)$. It also follows trivially from (1) that $U(s)$ is strictly concave in $s$, whenever the utility function $u$ is strictly concave in consumption. As a result, the second-order condition for a maximum holds and $s^{*}$ is unique. For example, if $r=\delta$, then as is well known, saving is used as a device to perfectly eliminate fluctuations in consumption over time. 
Now assume that labor income at date $t=1$ is risky, say $\widetilde{y}_{1}$, where $E \widetilde{y}_{1}=y_{1}$. In this case, it is not possible to perfectly smooth consumption over time. Indeed, consumption at date $t=1$ depends on the realized value of future labor income $\widetilde{y}_{1}$. Thus, the objective of the consumer becomes

$$
\max _{s} U(s) \equiv u\left(y_{0}-s\right)+\frac{1}{1+\delta} E u\left(\widetilde{y}_{1}+s(1+r)\right) .
$$

It follows in a straightforward manner from (3) that the optimal level of saving will necessarily increase whenever $E u^{\prime}\left(\widetilde{y}_{1}+s^{*}(1+r)\right) \geq u^{\prime}\left(y_{1}+s^{*}(1+r)\right)$, which can be guaranteed for any arbitrary values of $y_{1}$ and $r$, and any arbitrary mean- $y_{1}$ random variable if and only if $u^{\prime}$ is a convex function of consumption, i.e. if and only if $u^{\prime \prime \prime} \geq 0 .{ }^{12}$ This increased level of saving due to the labor income risk is precisely the precautionary part of total saving.

Some insight into this result is provided by Hanson and Menezes (1971), who related $u^{\prime \prime \prime}>0$ to the utility premium of Friedman and Savage (1948). The utility premium simply measures the difference in utility between $u(w)$ and $E u(w+\widetilde{\varepsilon})$ for any random wealth variable $\widetilde{\varepsilon}$. If $E \widetilde{\varepsilon} \leq 0$, this utility premium simply measures

\footnotetext{
${ }^{12}$ We will consider an "increase" in savings to be in the weak sense that savings does not fall. All of our results below extend to strict inequalities by well known methods. However, this leads to more complicated mathematical conditions, with no real gain in economic insight. Hence, only increases in savings in this weak sense are considered throughout the paper.
} 
the loss of utility from adding the risk $\widetilde{\varepsilon}$ to one's wealth. As such, we can refer to this utility premium as an intrapersonal measure of "pain" for adding the risk $\widetilde{\varepsilon} .13$ Prudence implies that the "pain" of the risk $\widetilde{\varepsilon}$ is lower at higher wealth levels. In the case of labor-income risk, the individual can reduce the "pain" of the riskiness of $\widetilde{y}_{1}$ by shifting a bit more wealth from date $t=0$ to the date $t=1$.

The analysis can now be extended to more general risk changes based on various orders of stochastic dominance. Denote the level of saving that maximizes (3) as $s_{y}$. Thus, $s_{y}$ is the solution to the first-order condition

$$
U^{\prime}(s)=-u^{\prime}\left(y_{0}-s\right)+\frac{1+r}{1+\delta} E u^{\prime}\left(\widetilde{y}_{1}+s(1+r)\right)=0
$$

Consider a change in random wealth at date $t=1$ from $\widetilde{y}_{1}$ to $\widetilde{x}_{1}$, where $\widetilde{y}_{1}$ dominates $\widetilde{x}_{1}$ via $N^{t h}$-order stochastic dominance. As a trivial example, suppose $\widetilde{y}_{1}=y_{1}$ and $\widetilde{x}_{1}=x_{1}$ are both constants, with $y_{1}>x_{1}$. It follows trivially from (2) that saving will increase whenever $u^{\prime}$ is decreasing, i.e. $u^{\prime \prime} \leq 0$. But this also turns out to be a necessary and sufficient condition for any stochastic change in labor income for which $\widetilde{y}_{1}$ dominates $\widetilde{x}_{1}$ by first-order stochastic dominance (FSD).

Using (4), it follows that saving will increase whenever $E u^{\prime}\left(\widetilde{y}_{1}+s_{y}(1+r)\right) \leq$

\footnotetext{
${ }^{13}$ Eeckhoudt and Schlesinger (2006) introduce the utility premium as a measure of pain, and they use it to characterize higher-order preference effects in much the same way as this characterization of prudence.
} 
$E u^{\prime}\left(\widetilde{x}_{1}+s_{y}(1+r)\right)$ for any arbitrary value of $r$. Under first-order stochastic dominance, this inequality holds for any arbitrary $\widetilde{y}_{1}$ and $\widetilde{x}_{1}$ exhibiting FSD if and only if $u^{\prime}$ is a decreasing function. In other words, a consumer always saves more when future labor income becomes riskier in the sense of FSD if and only if the consumer is risk-averse.

But what about higher order stochastic changes in future labor income? Proposition 1 below extends the analysis to any arbitrary degree of stochastic dominance $N$, where $\widetilde{y}_{1}$ dominates $\widetilde{x}_{1}$ via $N^{t h}$-order stochastic dominance (NSD). The proof of the Proposition hinges on the following well known equivalence result:

\section{NSD Equivalence ${ }^{14}$}

The following two statements are equivalent

(i) $\widetilde{y}_{1}$ dominates $\widetilde{x}_{1}$ via NSD

(ii) $\operatorname{Ef}\left(\widetilde{y}_{1}\right) \leq E f\left(\widetilde{x}_{1}\right)$ for any arbitrary function $f$ such that $\operatorname{sgn}\left(d^{n} f(t) / d t^{n}\right)=$ $(-1)^{n}$, for all $n=1,2, \ldots, N$.

We are now able to state our main result. For notational convenience, denote $f^{(n)}(t) \equiv d^{n} f(t) / d t^{n}$

Proposition 1 Given a two-period consumption and saving problem as specified in (3), with risky future labor income $\widetilde{y}_{1}$ or $\widetilde{x}_{1}$, the following two statements are equiv-

\footnotetext{
${ }^{14}$ See, for example, Ingersoll (1987).
} 
alent:

(i) The optimal level of saving under $\widetilde{x}_{1}$ is always as least as high as under $\widetilde{y}_{1}$, for every utility function $u$ such that $\operatorname{sgn}\left[u^{(n)}(t)\right]=(-1)^{n+1}$, for $n=1,2, \ldots, N+1$

(ii) $\widetilde{y}_{1}$ dominates $\widetilde{x}_{1}$ via $N S D$.

Proof. It is required that $u^{\prime}>0$ and $u^{\prime \prime}<0$ for $(3)$ to be well defined. The result here follows by simply defining $f(t) \equiv u^{\prime}\left(t+s_{y}(1+r)\right)$ in the NSD equivalence statements, where $s_{y}$ is the solution to (4).

Proposition 1 can be easily extended to the following Corollary, which follows in a straightforward manner by using Ekern's definition of an increase in $N^{\text {th }}$-degree risk.

Corollary 1: Given a two-period consumption and saving problem as specified in (3), with risky future labor income $\widetilde{y}_{1}$ or $\widetilde{x}_{1}$, the following two statements are equivalent:

(i) The optimal level of saving under $\widetilde{x}_{1}$ is as least as high as under $\widetilde{y}_{1}$, for every utility function $u$ such that $\operatorname{sgn}\left[u^{(N+1)}(t)\right]=(-1)^{N}$

(ii) $\widetilde{x}_{1}$ is an $N^{\text {th }}$-degree increase in risk over $\widetilde{y}_{1}$.

Note that in the "standard" model of precautionary saving, in which the change is from a fixed future labor income to a random one, one can think of $\widetilde{y}_{1}=y_{1}$ and $E \widetilde{x}_{1}=y_{1}$. This is just a special case of Proposition 1 with $N=2$. Since 
the precautionary part of saving is zero when the future labor income is not risky, it follows that $u^{\prime \prime \prime} \geq 0$ is both necessary and sufficient for the existence of precautionary saving.

Returning to the examples of risk used in section 2, it follows that prudence is both necessary and sufficient to guarantee that any second-order increase in laborincome risk leads to higher precautionary saving. On the other hand, a higher probability of unemployment or a reduction in unemployment benefits will lead to higher precautionary saving under risk aversion alone, since these both represent first-order risk changes. Prudence is not necessary in this case. Even the oft maligned quadratic utility function, which is not prudent, is sufficient to generate precautionary saving in this case.

For cases with third-order risk changes, prudence alone is not sufficient to generate an increase in precautionary saving. This would require the condition of "temperance," $u^{(4)}(t) \leq 0 .{ }^{15}$ Thus, for example, if a switch to a flat tax on income generated a reduction in downside risk, as described in section 2 , it would lead to less precautionary saving under temperance.

\footnotetext{
${ }^{15}$ Although not much has been written about higher-order effects, there are a few papers. The term "temperance" follows from Kimball (1992). The condition $u^{(5)}(t) \geq 0$ is referred to as "edginess" (Lajeri-Chaherli, 2004). Although these authors find such conditions as necessary for various types of behavior, they do not offer any settings under which these conditions are sufficient for anything.
} 


\section{$4 \quad$ Risky Interest Rates}

Now assume that the interest paid on savings is itself random, rather than fixed. Even so-called "risk-free" bonds are typically only risk-free with respect to any default risk. There still might be some risk that the market rates will change, or that real purchasing power cannot be guaranteed due to unexpected inflation. Rothschild and Stiglitz (1971) considered a savings model with income only at date $t=0$. At this date, the consumer decides how much to consume and how much to save, for consumption at date $t=1$. Any amount saved earns a rate of interest $\widetilde{r}$, where it is assumed that $\widetilde{r}>-1$. The consumer's objective can thus be written as

$$
\max _{s} U(s) \equiv u\left(y_{0}-s\right)+\frac{1}{1+\delta} E u(s \widetilde{R})
$$

where, for ease of notation, $\widetilde{R}$ denotes the gross rate of interest, $\widetilde{R}=(1+\widetilde{r})$.

The first-order condition for (5) is

$$
U^{\prime}(s) \equiv-u^{\prime}\left(y_{0}-s\right)+\frac{1}{1+\delta} E\left[u^{\prime}(s \widetilde{R}) \widetilde{R}\right]=0 .
$$

It is again straightforward to show that $U(s)$ is strictly concave, so that second-order conditions for a maximum easily hold and any solution to (6) is unique. It is assumed 
that the optimal level of saving $s^{*}$ is strictly positive, with $s^{*}<y_{0}{ }^{16}$

Rothschild and Stiglitz (1971) consider a change in the distribution of $\widetilde{R}$ to one that is a mean-preserving increase in risk, as defined by their earlier paper Rothschild and Stiglitz (1970). We examine a more general stochastic change in interest from say $\widetilde{R}_{a}$ to $\widetilde{R}_{b}$. First, consider the case where $\widetilde{R}_{a}$ dominates $\widetilde{R}_{b}$ by NSD.

Proposition 2 Let $s_{i}$ denote the optimal level of saving for (5) when $\widetilde{R}=\widetilde{R}_{i}$, for $i=a, b$. The following two statements are equivalent:

(i) The optimal level of saving under $\widetilde{R}_{b}$ is as least as high as under $\widetilde{R}_{a}$, for every utility function $u$ such that $\left[-t u^{(n+1)}(t)\right] / u^{(n)} \geq n \quad$ for all $n=1,2, \ldots, N$

(ii) $\widetilde{R}_{a}$ dominates $\widetilde{R}_{b}$ via NSD.

Proof. From (6) and the concavity of $U(s)$, it follows that $s_{b} \geq s_{a}$ whenever $E\left[u^{\prime}\left(s_{a} \widetilde{R}_{b}\right) \widetilde{R}_{b}\right] \geq E\left[u^{\prime}\left(s_{a} \widetilde{R}_{a}\right) \widetilde{R}_{a}\right] . \quad$ From NSD equivalence, this will hold for all $y_{0}$ whenever the function $h(R) \equiv R u^{\prime}\left(s_{a} R\right)$ satisfies the property that $\operatorname{sgn}\left(h^{(n)}(R)\right)=$ $(-1)^{n}$ for all $n=1,2, \ldots, N$. We proceed by induction. For $N=1$, straightforward calculation shows that $h^{\prime}(R)=s_{a} R u^{\prime \prime}\left(s_{a} R\right)+u^{\prime}\left(s_{a} R\right)$. Thus $h^{\prime}(R) \leq 0$ holds for all $R$ if and only if relative risk aversion is greater than one: $-t u^{\prime \prime}(t) / u^{\prime}(t) \geq 1, \forall t>0$.

\footnotetext{
${ }^{16}$ Since $\widetilde{r}>-1$, the assumption of $s^{*}>0$ avoids any issues associated with bankruptcy. Taken together with the assumption that $s^{*}<y_{0}$, this implies that the consumer must have positive consumption in each period.
} 
For any $n>1$, it follows from standard induction arguments that

$$
h^{(n)}(R)=\left(s_{a}\right)^{n} R u^{(n+1)}\left(s_{a} R\right)+n\left(s_{a}\right)^{n-1} u^{(n)}\left(s_{a} R\right) .
$$

Since by assumption $s_{a}$ is strictly positive, it follows that $h^{(n)}(R) \leq[\geq] 0$ for all $R$ if and only if $-t u^{(n+1)}(t) / u^{(n)}(t) \geq[\leq] n, \forall t>0$, so long as $u^{(n)}(t) \neq 0 . \quad$ Applying NSD equivalence, it follows that $\widetilde{R}_{a}$ dominates $\widetilde{R}_{b}$ via NSD is equivalent to $E\left[u^{\prime}\left(s_{a} \widetilde{R}_{b}\right) \widetilde{R}_{b}\right] \geq E\left[u^{\prime}\left(s_{a} \widetilde{R}_{a}\right) \widetilde{R}_{a}\right]$ for all utility $u$ such that $-t u^{(n+1)}(t) / u^{(n)}(t) \geq n$, $\forall t>0, \forall n=1,2, \ldots, N$. The result then follows immediately.

If $u^{(n+1)}(t)=0$ for all $t>0$, then $h^{(n)}(R)$ is a constant, possibly identical to zero. Consequently, any $n^{\text {th }}$-degree increase risk for interest rates will have no effect on the level of optimal level of saving.

In a manner similar to Corollary 1, one can induce from Proposition 2 the following result.

Corollary 2: Let $s_{i}$ denote the optimal level of saving for (5) when $\widetilde{R}=\widetilde{R}_{i}$, for $i=a, b$. The following two statements are equivalent:

(i) The optimal level of saving under $\widetilde{R}_{b}$ is as least as high as under $\widetilde{R}_{a}$, for every utility function $u$ such that $\left[-t u^{(N+1)}(t)\right] / u^{(N)}(t) \geq N$, so long as $u^{(N)}(t) \neq 0 \quad \forall t>0$. For $u^{(N)}(t)=0$, the saving levels will be identical. 
(ii) $\widetilde{R}_{b}$ is an $N^{\text {th }}$-degree increase in risk over $\widetilde{R}_{a}$.

The result of Rothschild and Stiglitz (1971) is a special case of Corollary 2, with $N=2$ : If $\widetilde{R}_{b}$ is a mean-preserving increase in risk over $\widetilde{R}_{a}$, then $s_{b} \geq s_{a}$ whenever relative prudence exceeds two. As another example, suppose that economic forecasters predict that economic performance will be less than previously expected. In this case, we might expect that $\widetilde{R}_{b}$ is first-order increase in risk over $\widetilde{R}_{a}$. Hence, saving will increase $\left(s_{b} \geq s_{a}\right)$ whenever relative risk aversion exceeds one.

It is noteworthy to compare the results from the two different set-ups. For the sake of concreteness, consider an increase in third-order risk, $N=3$. In the model where the rate of interest was fixed, but future labor income was risky, it was required only that the consumer be temperate, in order for a third-order increase in risk in the distribution of future labor income to increase precautionary saving.

Consider the model in which only the interest rate is risky. This case would correspond to changes in the skewness of short-term interest rates. Here there are, in a sense, two effects. This can be seen by examining (7), which can be written as $h^{\prime \prime \prime}(R)=\left(s_{a}\right)^{3} R u^{\prime \prime \prime \prime}\left(s_{a} R\right)+n\left(s_{a}\right)^{2} u^{\prime \prime \prime}\left(s_{a} R\right)$. If $u$ were cubic with $u^{\prime \prime \prime}>0$ but $u^{\prime \prime \prime \prime}=0$, it would follow that $h^{\prime \prime \prime}(R)>0$ due to prudence. In this case, an individual who is prudent would save less. The reason for this is that savings itself would increase the level of third-order riskiness in second-period consumption. Thus, the 
individual would opt for more consumption at date $t=0$ (i.e. less saving). This can viewed as a type of substitution effect, due to the deterioration (increased thirdorder riskiness) of the saving instrument. On the other hand, if the consumer is temperate, $u^{\prime \prime \prime \prime}<0$, then the extra third-order risk for consumption at date $t=1$ will induce precautionary saving. We can refer to this as a precautionary effect. For the net effect to be an increase in saving, the precautionary effect must dominate, which will be the case if and only if relative temperance exceeds three. ${ }^{17}$

The case with $N=3$ thus requires more than just relative prudence in excess of two. On the other hand, consider the simple case of a first-order change in interest-rate risk, such as the stochastically lower interest rates mentioned in section 2. Here, relative prudence in excess of two is not even necessary, so long as relative risk aversion exceeds one. If the consumer has logarithmic utility (with relative risk aversion equal to one), then first-order risk changes will have no effect on saving: the positive precautionary effect will be precisely offset by the negative substitution effect.

It is interesting to note as example a few particular utility functions, that are

\footnotetext{
${ }^{17}$ For $N=4$, this would require $-t u^{(5)}(t) / u^{(4)}(t) \geq 5$, which using nomenclature from LajeriChaherli (2004), can be described as the measure of "relative edginess" exceeding five. For $n \geq 6$, we are unaware of any literature describing or naming the measure $-t u^{(n)}(t) / u^{(n-1)}(t)$. However, the general condition under expected utility that $\operatorname{sgn}\left[u^{(n)}\right]=(-1)^{n+1}$ is discussed by Caballe and Pomansky (1995), who label $-u^{(n)}(t) / u^{(n-1)}(t)$ as a measure of " $n^{t h}$-degree risk aversion." We thus might wish to label $-t u^{(n)}(t) / u^{(n-1)}(t)$ as a measure of "relative $n^{t h}$-degree risk aversion."
} 
quite common within the macroeconomics literature.

Example 1: Consider the case of quadratic utility, with $u(t)=t-k t^{2}$, where $k>0$ and where $t$ is restricted to $t<(2 k)^{-1}$. Further restricting $t$ such that $(4 k)^{-1}<t<$ $(2 k)^{-1}$ then will lead to relative risk aversion exceeding one, so that any first-degree increase in risk from $\widetilde{R}_{b}$ to $\widetilde{R}_{a}$ will increase saving. But an increase in $N^{t h}$-degree risk for any $N$ other than $N=1$, will lead to no change in saving, since relative prudence is zero.

Example 2: For utility that belongs to the class of functions exhibiting constant absolute risk aversion (CARA), with $-t u^{\prime \prime}(t) / u^{\prime}(t)=\theta t \quad \forall t>0$, where $\theta>0$, it follows that $\left[-t u^{(N+1)}(t)\right] / u^{(N)}(t)=\theta t$ as well. Thus, an $N^{t h}$-degree increase in interest-rate risk will lead to higher saving only if wealth is sufficiently high; in particular $t \geq N / \theta$.

Example 3: For utility that belongs to the often-used class of functions exhibiting constant relative risk aversion (CRRA), with $-t u^{\prime \prime}(t) / u^{\prime}(t)=\gamma \quad \forall t>0$, where $\gamma>0$, it follows that $\left[-t u^{(N+1)}(t)\right] / u^{(N)}(t)=(\gamma-1)+N$, which of course exceeds $N$ whenever $\gamma \geq 1 .{ }^{18}$ Thus, for CRRA utility, relative risk aversion larger than one is both necessary and sufficient for any $N^{\text {th }}$-degree increase in risk to increase the level of saving.

\footnotetext{
${ }^{18}$ CRRA utility takes the form $u(t)=\ln t$ or $u(t)=\frac{1}{1-\gamma} t^{1-\gamma}$ for $\gamma \neq 1$.
} 


\section{Concluding Remarks}

This paper examined two models of saving with a risky future. When future labor income is risky, a stochastic increase in $N^{\text {th }}$-degree risk leads to more saving if and only if $\operatorname{sgn}\left[u^{(N+1)}\right]=(-1)^{N}$. When there is an increase in $N^{t h}$-degree risk in the return on savings, this condition is no longer sufficient, and instead it is required that the measure of relative $(N+1)^{s t}$-degree risk aversion exceed $N$, i.e., $\left[-t u^{(N+1)}(t)\right] / u^{(N)}(t) \geq N$. This condition guarantees a precautionary effect that is strong enough to increase the level of saving.

Prudence has often been considered as synonymous with a precautionary demand for saving in the face of increased labor-income risk. However, this turns out to hold only for second-degree risk changes. For example, a higher probability of unemployment or other first-order risk changes would lead to an increased precautionary demand under the weaker condition of risk aversion.

Risk changes of degree higher than two have been examined empirically for interest-rate risk but not examined very much for labor income risk. This might be due, in part, to not having any theoretical predictions about what such risk changes would entail. Hopefully this paper can contribute to further research in this direction. 


\section{References}

[1] Browning, M., Lusardi A., 1996. Household saving: Microtheories and macro facts. Journal of Economic Literature 36, 1797-1855.

[2] Caballé, J.,Pomansky, A., 1995. Mixed risk aversion. Journal of Economic Theory $71,485-513$.

[3] Carroll, C., Kimball, M., 2008. Precautionary saving and precautionary wealth. In: S. Durlauf, N., Blume, L. E. (Eds.), The New Palgrave Dictionary of Economics, 2nd Edition, MacMillan, London.

[4] Carroll, C., Dynan, K., Krane, S., 2003. Unemployment risk and precautionary wealth: Evidence from households' balance sheets. Review of Economics and Statistics 85, 586-604.

[5] Davies, J., Hoy, M., 2002. Flat rate taxes and inequality measurement. Journal of Public Economics 84, 33-46.

[6] Dutta, K., Babbel, D., 2005. Extracting probablistic information from the prices of interest rate options: Testing distributional assumptions. Journal of Business $78,841-870$. 
[7] Eeckhoudt, L. Schlesinger, H., 2006. Putting risk in its proper place. American Economic Review 96, 280-289.

[8] Ekern, S., 1980. Increasing $N^{\text {th }}$ degree risk. Economics Letters 6, 329-333.

[9] Engen, E., Gruber, J., 2001. Unemployment insurance and precautionary saving. Journal of Monetary Economics 47, 545-579.

[10] Engle, R., 1982. Autoregressive conditional heteroskedasticity. with estimates of United Kingdom inflation. Econometrica 50, 987-1008

[11] Friedman, M., Savage, L., 1948. The utility analysis of choices involving risk. Journal of Political Economy 56, 279-304.

[12] Gollier, Christian The Economics of Risk and Time. Cambridge: MIT Press, 2001.

[13] Gray, S., 1996. Modeling the conditional distribution of interest rates as a regime-switching process. Journal of Financial Economics 42, 27-62.

[14] Guiso, L., Jappelli, T., Pistaferri, L., 2002. An empirical analysis of earnings and employment risk. Journal of Business and Economic Statistics 20, 241-253.

[15] Hahn, F., 1970. Savings and uncertainty. Review of Economic Studies 37, 21-24. 
[16] Hanson, D., and Menezes, C., 1971. On a neglected aspect of the theory of risk aversion. Western Economic Journal 9, 211-217.

[17] Huggett, M., Ospina, S., 2001. Aggregate precautionary saving: When is the third derivative irrelevant? Journal of Monetary Economics 48, 373-396.

[18] Ingersoll, J., 1987. Theory of Financial Decision Making. Rowman \& Littlefield, New Jersey..

[19] Kimball, M., 1990. Precautionary savings in the small and in the large. Econometrica 58, 53-73.

[20] Kimball, M., 1992. Precautionary motives for holding assets, in The New Palgrave Dictionary of Money and Finance. P. Newman, M. Milgate, and J. Falwell, eds., MacMillan, London.

[21] Lajeri-Chaherli, F., 2004. Proper prudence, standard prudence and precautionary vulnerability. Economics Letters 82, 29-34.

[22] Leland, H., 1968. Saving and uncertainty: The precautionary demand for saving. Quarterly Journal of Economics 82, 465-473.

[23] Levhari, D., Srinivasan, T., 1969. Optimal saving under uncertainty. Review of Economic Studies 36, 153-163. 
[24] Lusardi, A., 1988. On the importance of precautionary saving. American Economic Review 88, 448-453.

[25] Menezes, C., Geiss, C., Tressler, J., 1980. Increasing downside risk." American Economic Review 70, 921-932.

[26] Parker, J., Preston, B., 2005. Precautionary saving and consumption fluctuations. American Economic Review 95, 1119-1143.

[27] Phelps, E., 1962. The accumulation of risky capital: A sequential utility analysis. Econometrica 30, 729-743.

[28] Rothschild, M., Stiglitz, J., 1970. Increasing risk: I. A Definition." Journal of Economic Theory 2, 225-243.

[29] Rothschild, M., Stiglitz, J., 1971. Increasing risk: II. Its economic consequences. Journal of Economic Theory 3, 66-84.

[30] Sandmo, A., 1970. The effect of uncertainty on saving decisions." Review of Economic Studies 37, 353-360.

[31] Storesletten, K., Telmer, C., Yaron, A., 2004. Cyclical dynamics in idiosyncratic labor market risk. Journal of Political Economy 112, 695-717. 


\section{CESifo Working Paper Series}

for full list see www.cesifo-group.org/wp

(address: Poschingerstr. 5, 81679 Munich, Germany, office@cesifo.de)

2325 Helmuth Cremer, Philippe De Donder, Dario Maldonado and Pierre Pestieau, Forced Saving, Redistribution and Nonlinear Social Security Schemes, June 2008

2326 M. Hashem Pesaran and Paolo Zaffaroni, Optimal Asset Allocation with Factor Models for Large Portfolios, June 2008

2327 Harald Badinger and Peter Egger, Horizontal versus Vertical Interdependence in Multinational Activity, June 2008

2328 Jan K. Brueckner and Harris Selod, A Theory of Urban Squatting and Land-Tenure Formalization in Developing Countries, June 2008

2329 Paolo M. Panteghini, Corporate Debt, Hybrid Securities and the Effective Tax Rate, June 2008

2330 Guglielmo Maria Caporale, Juncal Cuñado and Luis A. Gil-Alana, Modelling Long-Run Trends and Cycles in Financial Time Series Data, June 2008

2331 Avi Ben-Bassat and Momi Dahan, Social Identity and Voter Turnout, June 2008

2332 Martin R. West and Ludger Wößmann, "Every Catholic Child in a Catholic School”: Historical Resistance to State Schooling, Contemporary Private Competition, and Student Achievement across Countries, June 2008

2333 Erkki Koskela and Panu Poutvaara, Outsourcing and Labor Taxation in Dual Labor Markets, June 2008

2334 Philippe Choné and Laurent Linnemer, Optimal Litigation Strategies with Signaling and Screening, June 2008

2335 Albert Solé-Ollé and Pilar Sorribas-Navarro, Does Partisan Alignment Affect the Electoral Reward of Intergovernmental Transfers?, June 2008

2336 Antonio Cabrales and Piero Gottardi, Markets for Information: Of Inefficient Firewalls and Efficient Monopolies, June 2008

2337 Sumon Majumdar and Sharun W. Mukand, The Leader as Catalyst - on Leadership and the Mechanics of Institutional Change, June 2008

2338 Ulrich Hange, Tax Competition, Elastic Labor Supply, and Growth, June 2008

2339 Guy Laroque and Bernard Salanié, Does Fertility Respond to Financial Incentives?, June 2008 
2340 Adriano Paggiaro, Enrico Rettore and Ugo Trivellato, The Effect of Extending the Duration of Eligibility in an Italian Labour Market Programme for Dismissed Workers, June 2008

2341 Helmut Seitz, Minimum Standards, Fixed Costs and Taxing Autonomy of Subnational Governments, June 2008

2342 Robert S. Chirinko, Leo de Haan and Elmer Sterken, Asset Price Shocks, Real Expenditures, and Financial Structure: A Multi-Country Analysis, July 2008

2343 Wolfgang Leininger, Evolutionarily Stable Preferences in Contests, July 2008

2344 Hartmut Egger and Udo Kreickemeier, Fairness, Trade, and Inequality, July 2008

2345 Ngo Van Long and Bodhisattva Sengupta, Yardstick Competition, Corruption, and Electoral Incentives, July 2008

2346 Florian Baumann, Employment Protection: The Case of Limited Enforceability, July 2008

2347 Alessandro Balestrino, Cinzia Ciardi and Claudio Mammini, On the Causes and Consequences of Divorce, July 2008

2348 Dirk Schindler and Benjamin Weigert, Insuring Educational Risk: Opportunities versus Income, July 2008

2349 Lammertjan Dam and Ben J. Heijdra, The Environmental and Macroeconomic Effects of Socially Responsible Investment, July 2008

2350 Avner Greif, Contract Enforcement and Institutions among the Maghribi Traders: Refuting Edwards and Ogilvie, July 2008

2351 Helmuth Cremer, Philippe De Donder, Dario Maldonado and Pierre Pestieau, Habit Formation and Labor Supply, July 2008

2352 Francesco Menoncin and Paolo M. Panteghini, The Johansson-Samuelson Theorem in General Equilibrium: A Rebuttal, July 2008

2353 Michael Kaganovich and Itzhak Zilcha, Alternative Social Security Systems and Growth, July 2008

2354 Keith Blackburn, Kyriakos C. Neanidis and M. Emranul Haque, Corruption, Seigniorage and Growth: Theory and Evidence, July 2008

2355 Edward Castronova, A Test of the Law of Demand in a Virtual World: Exploring the Petri Dish Approach to Social Science, July 2008

2356 Harald Badinger and Peter Egger, GM Estimation of Higher-Order Spatial Autoregressive Processes in Cross-Section Models with Heteroskedastic Disturbances, July 2008 
2357 Wolfgang Buchholz and Jan Schumacher, Discounting the Long-Distant Future: A Simple Explanation for the Weitzman-Gollier-Puzzle, July 2008

2358 Luca Anderlini, Leonardo Felli and Alessandro Riboni, Statute Law or Case Law?, July 2008

2359 Guglielmo Maria Caporale, Davide Ciferri and Alessandro Girardi, Are the Baltic Countries Ready to Adopt the Euro? A Generalised Purchasing Power Parity Approach, July 2008

2360 Erkki Koskela and Ronnie Schöb, Outsourcing of Unionized Firms and the Impacts of Labour Market Policy Reforms, July 2008

2361 Francisco Alvarez-Cuadrado and Ngo Van Long, A Permanent Income Version of the Relative Income Hypothesis, July 2008

2362 Gabrielle Demange, Robert Fenge and Silke Uebelmesser, Financing Higher Education and Labor Mobility, July 2008

2363 Alessandra Casarico and Alessandro Sommacal, Labor Income Taxation, Human Capital and Growth: The Role of Child Care, August 2008

2364 Antonis Adam, Manthos D. Delis and Pantelis Kammas, Fiscal Decentralization and Public Sector Efficiency: Evidence from OECD Countries, August 2008

2365 Stefan Voigt, The (Economic) Effects of Lay Participation in Courts - A Cross-Country Analysis, August 2008

2366 Tobias König and Andreas Wagener, (Post-)Materialist Attitudes and the Mix of Capital and Labour Taxation, August 2008

2367 Ximing Wu, Andreas Savvides and Thanasis Stengos, The Global Joint Distribution of Income and Health, August 2008

2368 Alejandro Donado and Klaus Wälde, Trade Unions Go Global!, August 2008

2369 Hans Gersbach and Hans Haller, Exit and Power in General Equilibrium, August 2008

2370 Jan P.A.M. Jacobs and Jan-Egbert Sturm, The Information Content of KOF Indicators on Swiss Current Account Data Revisions, August 2008

2371 Oliver Hülsewig, Johannes Mayr and Timo Wollmershäuser, Forecasting Euro Area Real GDP: Optimal Pooling of Information, August 2008

2372 Tigran Poghosyan and Jakob de Haan, Determinants of Cross-Border Bank Acquisitions in Transition Economies: A Latent Class Analysis, August 2008

2373 David Anthoff and Richard S.J. Tol, On International Equity Weights and National Decision Making on Climate Change, August 2008 
2374 Florian Englmaier and Arno Schmöller, Reserve Price Formation in Online Auctions, August 2008

2375 Karl Farmer, Birgit Friedl and Andreas Rainer, Effects of Unilateral Climate Policy on Terms of Trade, Capital Accumulation, and Welfare in a World Economy, August 2008

2376 Monika Bütler, Stefan Staubli and Maria Grazia Zito, The Role of the Annuity’s Value on the Decision (Not) to Annuitize: Evidence from a Large Policy Change, August 2008

2377 Inmaculada Martínez-Zarzoso, The Impact of Urbanization on $\mathrm{CO}_{2}$ Emissions: Evidence from Developing Countries, August 2008

2378 Brian Roberson and Dmitriy Kvasov, The Non-Constant-Sum Colonel Blotto Game, August 2008

2379 Ian Dew-Becker, How Much Sunlight Does it Take to Disinfect a Boardroom? A Short History of Executive Compensation Regulation, August 2008

2380 Cécile Aubert, Oliver Falck and Stephan Heblich, Subsidizing National Champions: An Evolutionary Perspective, August 2008

2381 Sebastian Buhai, Miguel Portela, Coen Teulings and Aico van Vuuren, Returns to Tenure or Seniority?, August 2008

2382 Erkki Koskela and Jan König, Flexible Outsourcing, Profit Sharing and Equilibrium Unemployment, August 2008

2383 Torberg Falch and Justina AV Fischer, Does a Generous Welfare State Crowd out Student Achievement? Panel Data Evidence from International Student Tests, September 2008

2384 Pedro Gomes and François Pouget, Corporate Tax Competition and the Decline of Public Investment, September 2008

2385 Marko Koethenbuerger, How Do Local Governments Decide on Public Policy in Fiscal Federalism? Tax vs. Expenditure Optimization, September 2008

2386 Ronald McKinnon and Gunther Schnabl, China’s Exchange Rate Impasse and the Weak U.S. Dollar, September 2008

2387 Yan-Leung Cheung, Yin-Wong Cheung and Alan T.K. Wan, A High-Low Model of Daily Stock Price Ranges, September 2008

2388 Louis Eeckhoudt and Harris Schlesinger, Changes in Risk and the Demand for Saving, September 2008 